\title{
SOBRE O PROJETO POLÍTICO PEDAGÓGICO: a flexibilização curricular ${ }^{1}$ ON THE PEDAGOGICAL POLICIES PROJECT: syllabus flexibility
}

\author{
Manuela Eugênio Maia - manumaia@yahoo.es \\ Pedagoga e Bibliotecária. Mestre em Educação. Professora da UFPB \\ Maria Elizabeth Baltar Carneiro de Albuquerque - ebaltar@openline.com.br \\ Bibliotecária e Mestre em Biblioteconomia. Professora da UFPB \\ Comente este artigo no blog Ebibli = http://encontros-bibli-blog.blogspot.com/
}

\begin{abstract}
Resumo
Este artigo apresenta questões curriculares do curso de graduação em Biblioteconomia da Universidade Federal da Paraíba. O objetivo é analisar elementos que subsidiem a proposta de flexibilização curricular para o referido curso. Do ponto de vista metodológico, a pesquisa respalda-se em uma abordagem qualitativa, utilizando documentos legais (Leis, Pareceres, Editais e Resoluções) e documentos institucionais (materiais produzidos pela academia na área pedagógica voltada para discussões referentes ao PPP, currículo e flexibilização curricular e seus enlaces teóricos). Como proposta, verifica-se na flexibilização curricular uma ação estratégica na tentativa de garantir o diálogo permanente entre cursos de formação e mercado de trabalho, favorecendo, assim, a conexão com a realidade social na qual o aluno egresso será inserido. Além disso, a flexibilização curricular amplia o direito de escolha dos alunos, possibilita uma maior participação dos colegiados dos cursos e produz reflexão nos docentes quanto ao atendimento das necessidades internas dos próprios cursos de formação.
\end{abstract}

Palavras-chave: Projeto Político-Pedagógico. Flexibilização curricular. Biblioteconomia.

\section{INTRODUÇÃO}

Na sociedade atual, a informação cumpre papel essencial. Sua relevância inicia-se com o aprimoramento de técnicas que visam à confecção de materiais diversos em ampla quantidade na Europa. Referimo-nos, aqui, ao processo de explosão informacional ocorrida com a proliferação da imprensa com Gutemberg na Alemanha de 1450.

Esse processo constitui-se historicamente e produz efeito sobre a sociedade, refletindo em suas instituições como a família, a escola e o ambiente de trabalho. Sabe-se que a produção, a organização e a disseminação de materiais informacionais, em larga escala, criam maiores possibilidades de intercâmbio de idéias. Estas, por sua vez, aumentam, exponencialmente, a elaboração de mais informações. Desta forma, emerge um mercado em torno desse produto, que é edificado durante os séculos XVII, XVIII e XIX e consolida-se entre os séculos XX e XIX. É neste paradigma, o da disseminação e consumo da informação, que se baseia a sociedade atual. Por isso, não é estranho escutarmos referências, hoje em dia,

\footnotetext{
${ }^{1}$ Pesquisa realizada para o Trabalho de Conclusão do Curso de Biblioteconomia da Universidade Federal da Paraíba, sob a orientação da Profa.Maria Elizabeth B.C.de Albuquerque.
} 
do conceito de sociedade da informação. Por informação, compreendemos o conjunto de idéias impressas ou não e que produz significado. Nessa produção de significado, é inerente à informação a sua passagem para outras gerações e locais. Portanto, implícito ao conceito de informação estão as noções de tempo e espaço.

Nessa direção, com a sofisticação cada vez mais organizada da informação, as instituições sociais são orientadas a estabelecer em sua estrutura esse novo paradigma. Surgindo na Europa a partir do século XIII e se consolidando como corpo organizado no século XVIII, ao longo de sua história e constituição, as instituições de ensino não priorizaram a utilização de estratégias estruturais que aproximassem as problemáticas e dilemas sociais ao seu universo. Poderíamos explicar isto pelo fato de que as escolas iniciaram seus primeiros passos como ambiente de guarda de crianças abandonadas, tornandose local de aprendizagem de elementos informativos praticamente dois séculos de seu surgimento. Ainda assim, quando a escola introduziu o componente "aprendizagem", a preocupação dos educadores concentrava-se mais na quantidade de informações que a criança deveria absorver do que em sua qualidade. Isso quer dizer que, os elementos de aprendizagem escolares não possuíam aplicação ou relação com o ambiente social (ARIÈS, 1981; SNYDERS, 1974).

Ao mesmo tempo em que podemos observar uma tentativa de desvinculação entre a escola e a sociedade, o modelo social cada vez mais se ancorava no uso da informação. Em seus primórdios, as escolas dos séculos XIII-XIV tentavam garantir no seu ambiente um distanciamento do mundo real, promovendo em seu espaço um processo peculiar na formação dos alunos. Essa idéia continua entre os educadores durante os séculos seguintes. Obviamente, existiram pensadores que, em seus períodos históricos, opunham-se a este modelo, tais como Comenius (1592-1670) e Rousseau (1712-1778). Porém, é com Dewey (1859-1952), nos Estados Unidos, que se exporta o princípio da escola enquanto espaço educativo integrante e integrado ao mundo social. Nesse período (século XX), as escolas e universidades do mundo ocidental passaram a rever sua postura pedagógica. Nessa direção, as instituições de ensino começavam a discutir a relação das atividades escolares às necessidades sociais vigentes, por sinal, debate que na atualidade permeia as mesas redondas dos especialistas em educação.

Desta forma, uma das questões recentes diz respeito à relação entre o mundo social e o que deve ser aprendido ao mundo escolar (ensinar informações pertinentes e vinculadas à sociedade). Assim perguntamos: em que âmbito as instituições educacionais elaboram suas diretrizes que visam aproximar os dilemas sociais aos educacionais? 
Parece-nos claro que as universidades e as escolas, em seus formatos atuais, têm por finalidade aproximar a realidade do cotidiano social ao seu espaço na organização. Percebemos que isso ocorre de modo concreto por meio de seus currículos, a fim de produzir efeito nos sujeitos nelas envolvidos. Nesse intuito, entendemos currículo (SAVIANI, 1991, p. 23-24) como sendo todas as atividades nucleares que tratam da transmissão e assimilação dos conhecimentos sistematizados, que garantam ao sujeito da aprendizagem sua aproximação ao saber elaborado pela humanidade.

Refletindo essa questão, o debate acerca da mudança curricular nos cursos de graduação deve-se ao fato de atualização constante frente às demandas informacionais na sociedade atual. Assim, o antigo modelo de escola/universidade em que a informação cristaliza-se no tempo é cada vez mais, deixada de lado. Em seu lugar, seguindo o princípio da atualização, os centros de ensino partem do pressuposto de que a informação é a patrocinadora do movimento social.

É verdade que as discussões prosseguem na intenção de concretizar a exigência legal no que diz respeito à reformulação dos cursos de ensino superior no Brasil. Essa reformulação, prevista na Lei de Diretrizes e Bases da Educação Nacional (LDB), Lei n ${ }^{o}$ 9.394, de 20 de dezembro de 1996, em seu artigo 53, inciso II, encaminha as discussões para fixação dos currículos e programas dos cursos, visando às diretrizes gerais vigentes.

Nessa direção, o Ministério da Educação (MEC), por meio da Secretaria de Educação Superior (SESu), publica, em 1997, edital nº 4, convocando as Instituições de Ensino Superior (IES) a elaborarem e apresentarem novas propostas de diretrizes curriculares de seus cursos. $\mathrm{Na}$ realidade, este edital, diz respeito a uma primeira chamada para se pensar as diretrizes curriculares para os cursos superiores. Tal chamada baseia-se no inciso II do artigo 53 da LDB, Lei $n^{\circ}$ 9.394/96, no Decreto $n^{\circ} 2.026$, de 10 de outubro de 1996, e no artigo 14 do Decreto $n^{\circ} 2.306$, de 19 de agosto de 1997.

Surge então um problema: a organização curricular dos cursos deve ser promovida a partir do diálogo entre as diretrizes curriculares e a definição de uma proposta pedagógica (Projeto Político Pedagógico - PPP). Aqui cabe salientar que as diretrizes curriculares inserem-se no PPP, que deve contemplar o perfil do formando, as competências e habilidades que se deseja formar, duração dos cursos, flexibilização curricular, sistemas de avaliação, estágios e atividades complementares. Na atual conjuntura, observamos que o PPP do Curso de Biblioteconomia da Universidade Federal da Paraíba (UFPB) encontra-se em estágio adiantado, necessitando, contudo, definir, do ponto de vista das diretrizes curriculares, o aspecto referente à flexibilização. É neste ponto específico que recai a nossa inquietação: 
como auxiliar nas discussões concernentes à flexibilização curricular para o curso de Biblioteconomia da UFPB?

A partir de nossa inquietação, tivemos como objetivo geral de nosso estudo analisar elementos que subsidiem a proposta de flexibilização curricular para o curso de Biblioteconomia da UFPB. Para atender a essa proposta, fizemos uso de três objetivos específicos, a saber, proceder o levantamento de documentos legais e institucionais referentes às questões sobre o PPP, o currículo e a flexibilização curricular; analisar os elementos constitutivos do PPP, do currículo e da flexibilização curricular; sugerir pontos que norteiem a organização constitutiva da flexibilização curricular para o curso de Biblioteconomia da UFPB.

\section{O PROJETO POLÍTICO PEDAGÓGICO E SUAS DIRETRIZES}

Os incisos I, dos artigos 12, 13 e 14 da LDB, Lei $\mathrm{n}^{\circ}$ 9.394/96, tornam clara a necessidade de elaboração de proposta pedagógica para as instituições de ensino, sejam da educação básica (compreendendo a educação infantil, ensino fundamental e ensino médio) ao ensino universitário por meio das IES.

Enquanto projeto, o PPP é um elemento vital para reflexão e re-elaboração constante das propostas norteadoras das instituições de ensino. Este debate é inaugurado na década de 80, com o fim da ditadura militar (1964-84) e com o intenso processo de democratização social que vivia o Brasil, e conduz a uma reestruturação político-social no sentido de oferecer maiores e melhores condições educacionais para as classes menos favorecidas. Permite, assim, a ampliação do ensino, que tem início de forma desgovernada, com precárias condições materiais e humanas e com a excessiva burocratização. Esses elementos deságuam em altos índices de evasão e de repetência. Segundo Xavier e Amaral Sobrinho (1998), as seguintes questões começam a ser observadas como forma de repensar a educação e de almejar a sua qualidade: como racionalizar o sistema de ensino? Como pensar e orientar a centralidade da direção pedagógica? Como agir para o desenvolvimento das relações interpessoais e das disposições dos recursos humanos com formação adequada? Como eleger os materiais escolares e didáticos necessários, ou ainda como escolher instalações de qualidade? Quais condições são necessárias para propiciar um clima favorável ao processo ensino-aprendizagem? Quais os elementos de identificação dos cursos, explicitando valores e compromisso com os alunos e sociedade? 
Essas preocupações, entre outras, nortearam as discussões educacionais entre $1982 \mathrm{e}$ 1996, culminando em 20 de dezembro de 1996 com a promulgação da Lei no 9.394, a Lei de Diretrizes e Bases da Educação Nacional (LDB). Cabe salientar que neste documento são essenciais as preocupações relacionadas ao PPP como um momento de consolidação de projetos pedagógicos no âmbito de cada escola e de cada curso universitário. Neste estudo, discutiremos a flexibilização curricular que se encontra inserida no PPP, para as IES, especificamente, para o curso de Biblioteconomia da UFPB.

Segundo Freire $(1979,1996)$, o PPP é, antes de tudo, um instrumento coletivo para transformação do contexto escolar/universitário. Trata-se de um instrumento coletivo que enaltece a ação política social, pois possibilita aos docentes e à comunidade mecanismos de organização, visando a um mundo melhor a ser compartilhado por todos. O PPP é o resultado de discussões e reflexões que resultam na humanização e na conscientização de sujeitos históricos. Sua importância encontra-se na busca de uma sociedade melhor. Desta forma, o PPP assume uma tomada de posição diante da realidade social e humana, porquanto possui conteúdo ideológico. Trata-se de uma ação consciente e planejada, voltada para a criação de uma realidade futura.

Uma de suas características é a qualidade do ensino e, por isso, é inerente ao PPP a permanente qualificação e capacitação docente. Além disso, na elaboração do PPP, os atores sociais devem considerar o seu caráter de flexibilidade, característica fundamental da sociedade atual. No entanto, de acordo com Morin (2001), valores como honestidade, dignidade, justiça social, companheirismo, participação, transparência, decência e solidariedade devem estar presentes se pensarmos num projeto de formação humana e não só intelectual. É na busca desses valores que o PPP é entendido como ferramenta de coletividade, indo ao encontro da apropriação do conhecimento sistematizado até a ação prática social, tanto por intermédio dos professores como dos alunos.

Analisando em específico o curso de Biblioteconomia, o seu PPP, ao visar à formação intelectual, é propício que articule os componentes científicos, tecnológicos e culturais, numa compreensão humanizante do indivíduo integral, aos conhecimentos específicos de outros componentes curriculares, a saber, a informática, a pedagogia, a comunicação etc.

Nessa compreensão, o Conselho Nacional de Educação (CNE) e a Câmara de Educação Superior (CES), por meio da Lei $n^{\circ}$ 9.131/1995, dos Pareceres $n^{\circ} 492 / 2001$ e $n^{\circ}$ 1.363/2001 e da Resolução $n^{\circ}$ 19/2002, são contundentes quanto à orientação a ser seguida pelo curso de Biblioteconomia para a formulação do PPP: descrever o perfil dos formandos; discriminar as competências e habilidades gerais e específicas a serem desenvolvidas durante 
curso; estabelecer os conteúdos curriculares de formação geral e os conteúdos de formação específica ou profissionalizante; organizar o formato dos estágios que compõe o curso; identificar as características das atividades complementares; estruturar o curso quanto à carga horária, obedecendo aos princípios da flexibilização curricular; estabelecer as formas de avaliação.

\section{DIRETRIZES SOBRE AS QUESTÕES CURRICULARES}

Podemos entender o currículo como sendo todas as atividades centrais que envolvem a instituição escolar. Ele é o produto do processo de organização do conhecimento, estando permeado por mecanismos de constituição de identidades individuais e sociais. Desta forma, compreendendo o ser humano como ser histórico e passível de mudanças, o currículo apresenta-se como elemento flexível e contingencial à organização da sociedade e da educação.

Deste modo, os teóricos críticos do currículo como Giroux (1988) e Apple (1982) percebem a estreita relação entre currículo - ideologia - cultura - poder (MOREIRA; SILVA, 2002). Quando optamos por um tipo específico de formação escolar, estamos apontando para uma compreensão sobre a relação do sujeito com a sociedade da qual ele faz parte.

Ao concebermos as modificações curriculares de um curso, deve ficar claro para os docentes, a comunidade e os discentes qual a posição político-ideológica que norteará a formação dos alunos do curso e sua ação na sociedade.

Recentemente, ao lermos um artigo escrito por Carvalho (1999), observamos a profunda crítica acerca da formação e o efetivo exercício profissional do bibliotecário. A autora investigou o papel do bibliotecário em três Centros Populares localizados em Olinda e Recife. Os Centros Populares organizam-se como espaço de conhecimento dinâmico e integrativo, necessitando de uma postura bibliotecária que contemple a flexibilidade, a integração e a dialogicidade. Entretanto, a pesquisa realizada demonstra que o bibliotecário apresenta-se rígido em sua relação com o usuário (ausência de feedback), tem medo de correr risco, assume posição comodista e não tem interesse de mudar essa visão que se tem sobre ele. Além disso, prioriza o documento e destaca sua profissão como essencialmente técnica. As conseqüências dessa postura são o isolamento e a perda de espaços para atuação profissional. Para mudar isso, Carvalho (1999) aponta, como principal estratégia, a modificação dos currículos de Biblioteconomia. Nesta direção, a formação do bibliotecário necessita contemplar seu caráter humanístico ao invés de valer-se dos elementos 
fundamentalmente técnicos, permitindo ao bibliotecário refletir e agir a sua atividade de modo engajado com as mudanças político-sociais e econômicas que ocorrem em nosso país e no mundo.

Assim, é de fundamental importância a escolha de atividades acadêmicas que favoreçam ações de interação com a sociedade, pois, é para ela, que retornam os profissionais formados nas diversas instituições de formato educativo. Podemos começar a perceber que a elaboração do PPP não tem caráter permanente, devendo ser analisado periodicamente e modificado quando necessário. Desta maneira, as atividades acadêmicas são formatadas de modo a cumprir os encaminhamentos postos pelas discussões em torno do PPP. A cada necessidade de modificação dos currículos, o PPP também sofre alterações de modo a manter a coerência entre ação e reflexão social dos docentes, discentes e comunidade.

É nossa obrigação social e ética olhar para a formação de um bibliotecário participativo, engajado politicamente e, sobretudo, criativo. Ao se dominar o conhecimento técnico da área, este não deve ser o único elemento norteador da conduta do ator social bibliotecário. $\mathrm{O}$ contexto em que ele desenvolve suas atividades possibilitam muitas das respostas que ele necessita para o seu trabalho cotidiano.

Nessa direção, Souza (1995) é contundente ao dizer que se faz necessária uma imediata mudança dos currículos nos cursos de Biblioteconomia. A sociedade muda constantemente e, portanto, parece inconcebível a existência, ainda, de um currículo pensado e estruturado no modelo de sociedade tecnicista dos anos 70. A realidade social mostra-se dinâmica e, se não agirmos para a formação de um bibliotecário com tal característica, correse o risco desta profissão desaparecer.

\section{FLEXIBILIZAÇÃO CURRICULAR}

Ao pensar no profissional bibliotecário, parece-nos conveniente ampliar seus atributos, concebendo-o, na era atual, como aquele que é responsável em lidar com a informação em sua multiplicidade. Desta forma, é coerente afirmar que o curso de Biblioteconomia assume o enfoque da formação do Profissional da Informação (CARVALHO, 1999). Este profissional passa, portanto, a estar mergulhado no mar da informação, que deve ser tratada de modo efetivo para o usuário. Para nós, o campo direto de ação do bibliotecário está voltado para a elaboração e execução de atividades que envolvam abertamente a sua relação com o usuário. 
Cada vez mais este profissional pensa como o usuário, para que, de fato, o acesso, a disseminação e o uso da informação ocorram em sua plenitude.

Desta forma, a flexibilização curricular é essencial para as reformas curriculares dos cursos de graduação, pois atua como ponto de relação entre os cursos e as rápidas transformações sociais, econômicas, políticas, tecnológicas e culturais na sociedade atual. É na flexibilização que se encontra o ponto de interseção do contexto do ensino e dos cursos superiores com a busca pelo novo, considerando o entrelaçamento dos aspectos globais e locais. Nessa direção, há, no interior de cada curso, um estágio de permanente crítica à própria instituição e à sociedade, com a finalidade de acompanhar as constantes transformações da realidade, marcando intenso processo de ruptura dos atores sociais com práticas rígidas e lineares, que pouco acrescentam a formação humana e contextualizada dos sujeitos. Por isso, compreende-se que a flexibilização curricular alia-se à diversidade dos sujeitos e práticas, favorecendo o exercício concreto da autonomia universitária e da cidadania por meio da organização/gestão administrativa e pedagógica/docente, da produção do conhecimento, da melhoria da sua infra-estrutura e das condições de trabalho dos professores e da valorização da categoria docente (UNIVERSIDADE FEDERAL DE MINAS GERAIS, 2003). Cabe salientar que entendemos flexibilização curricular como um organismo legal a fim de que cada IES possa atualizar suas atividades curriculares de modo ágil, permitindo maior diálogo entre as necessidades do campo de trabalho e a formação acadêmica dos seus alunos.

Nesse sentido, a flexibilização é uma possibilidade de caminho que promove a qualidade social para a prática pedagógica, contribuindo para o fortalecimento do bem comum do espaço público no interior e no exterior da universidade. Nessa perspectiva, compreendese, portanto, o seu papel na concretização da formação de subjetividades dos sujeitos, marcando, nas diversas instâncias do currículo, a materialização do princípio da indissociabilidade entre o ensino, pesquisa e extensão.

Do ponto de vista da gestão (Artigos 43-57 da LDB), a flexibilização caracteriza-se como forte aliada na construção da identidade de cada curso, devendo este especificá-la e defini-la para melhor orientar na formulação do currículo (BRASIL, 1998). Porém, é importante esclarecer que a flexibilização do currículo não se resume a mera reorganização de um conjunto de disciplinas. Acrescentam-se a esse processo as atividades complementares, a escolha coerente e política de cada conteúdo de cada atividade acadêmica, que reflete, em seu cerne, a flexibilização e, sobretudo, o desenvolvimento de ações pedagógicas distribuídas ao longo do curso, permitindo a interface real entre ensino, pesquisa e extensão. Todos esses processos caminham na direção da formação de um curso que aproxime os sujeitos às suas 
experiências nas diversas possibilidades de trajetos permitidos dentro das relações intra e inter-institucionais. Desse modo, o papel do tutor-professor serve como elemento na condução dos sujeitos para melhor direção e diversificação na sua formação social e profisssional. Esta preocupação reflete, especialmente, a melhoria da qualidade de ensino para os alunos noturnos, diante das limitações impostas na sua formação acadêmica. É na tutoria acadêmica que a imagem da flexibilização curricular ganha importante papel como estratégia para viabilizá-la.

No que se refere à gestão, os princípios que orientam a flexibilização devem atender a "necessária revisão da legislação acadêmica, considerando-se que esta resulta das concepções que norteiam e definem o perfil da instituição" (UNIVERSIDADE FEDERAL DE MINAS GERAIS, 2003).

Para a avaliação, a flexibilização curricular contempla os mecanismos capazes de verificar a concretização do perfil acadêmico pretendido, contribuindo para a construção permanente do PPP de cada curso. Nessa direção, as atividades complementares assumem função essencial nessa formação. Dentre estas atividades, podemos citar: atividades de extensão, atividades de monitoria, atividades de pesquisa, disciplinas eletivas, estágios nãoobrigatórios, atividades em educação à distância (EAD), atividades de representação acadêmica e participação em seminários, jornadas, congressos, eventos, simpósios, cursos e oficinas. É muito importante, também, que cada curso elabore eventos internos, como cursos e oficinas de áreas afins como possibilidade de ampliar a formação dos alunos (FLEXIBILIZAÇÃO..., 2004).

\subsection{Da especificidade da Flexibilização: sua verticalidade e horizontalidade}

Primeiramente, gostaríamos de explicar que a escassez de literatura na área de flexibilização curricular levou-nos a tomar como parâmetro central de discussão o relatório elaborado pela Câmara Estendida de Graduação da Universidade Federal de Minas Gerais (UFMG).

Neste documento, afirma-se que a verticalidade e horizontalidade do currículo, o que demarca o processo de flexibilização curricular, visa a oferecer diversificação e maior autonomia tanto para os colegiados dos cursos quanto para os alunos. Essa idéia configurase,sobretudo, numa diminuição da hierarquização e da estratificação do saber. Anteriormente, na formação acadêmica dos alunos das IES, a noção de currículo estava associada a uma grade fixa. Com a proliferação dos diversos campos do saber, oriunda da explosão 
informacional a partir dos anos 50, a formação curricular por meio de grade vem sendo cada vez mais contestada.

A questão que se discute é a capacidade da universidade em conseguir abarcar toda a diversificação das informações produzidas pela sociedade em uma área específica do saber? Questiona-se, ainda, a possibilidade do curso de formação superior contemplar as mais diferentes especificidades pertencentes ao seu campo de saber. Temos a conciência que atualmente esta é uma tarefa bastante complexa e difícil. Desta forma, a flexibilização curricular seria o mecanismo legal para contemplar essa gama informacional, agregando valor a formação subjetiva de cada aluno e possibilitando um maior grau de especificidade em sua formação. Na flexibilização, tenta-se assegurar o espaço da universidade como campo aberto à produção, geração e disseminação do conhecimento, configurando-se cada vez mais como ambiente democrático, pois considera os desejos dos educandos para sua escolha de atuação no mercado de trabalho, bem como, imprimir um ritmo que seja compatível com suas condições sociais, econômicas e culturais (UNIVERSIDADE FEDERAL DE MINAS GERAIS, 2003). A geração de informação na sociedade atual é tão veloz que a utilização da flexibilização curricular vem garantir uma permanente atualização do currículo.

Nessa direção, o marco central da flexibilização é a quebra da rigidez posta pela formação curricular baseada em grade. Habitualmente, esta idéia gera problemas como a centralidade das IES como únicos centros de formação, o que não condiz com a verdade. Além disso, individualiza as atividades acadêmicas, direcionando-as para a visão do professor; tais atividades nem sempre estão conectadas aos interesses dos alunos nem tão pouco as exigências do mercado de trabalho. Acrescenta-se a esses problemas a fragmentação dos conteúdos e do próprio saber que se visa a formar. Segundo os membros da Câmara Estendida de Graduação (UNIVERSIDADE FEDERAL DE MINAS GERAIS, 2003), estas dificuldades são observadas nas avaliações dos professores, que nem sempre são viabilizadas na direção de uma continuidade progressiva do processo de ensino e aprendizagem. Geralmente, o que se observa é uma avaliação que submete o aluno a ações descontextualizadas, centralizando a organização pedagógica na figura do professor e inibindo a participação do aluno e sua capacidade de estruturação, interpretação, formulação de problemas e compreensão efetiva dos conteúdos.

Cabe ao professor, dentro do modelo de flexibilização curricular, "orientar, estimular e promover condições para que o aprendizado se faça de maneira estimulante para o aluno" (UNIVERSIDADE FEDERAL DE MINAS GERAIS, 2003).

Ao pensarmos em currículo, cabe observar as seguintes questões: 
1) Deve o currículo ser concebido como um sistema articulado, no qual se busque, além da transmissão de conteúdos, o desenvolvimento de habilidades básicas, específicas e globais, de atitudes formativas, de análise crítica e de percepção mais global da atuação do aluno como profissional e como membro da sociedade?

2) Há conhecimentos, habilidades específicas e atitudes formativas específicas de cada curso?

3) Há conhecimentos, habilidades específicas e atitudes formativas que extrapolam campos ou áreas específicas do saber?

4) Há necessidade de certo grau de especialidade em cada curso?

5) Há condições de se preservar conhecimentos, habilidades específicas e atitudes formativas de uma área profissional e, simultaneamente, possibilitar o acesso do aluno a esse mesmo conjunto em outra área profissional?

6) Em caso afirmativo, isso é importante e desejável do ponto de vista profissional e enquanto demanda social?

7) Como adequar o currículo ao dinamismo do conhecimento, da ciência e da prática profissional?

8) Como garantir que o currículo funcione como um fluxo articulado de aquisição de saber, num período finito de tempo, tendo como base a flexibilidade, a diversidade e o dinamismo? (UNIVERSIDADE FEDERAL DE MINAS GERAIS, 2003).

Observados estes pontos, a conceituação mais atual sobre currículo deve prescindir da flexibilidade, do interesse dos alunos e da conexão e interligação com diversas áreas do saber que mantenha a relação com o campo de formação específico. Desta forma, a flexibilização curricular permite ampliar a discussão para a formação do aluno em sua esfera implícita (currículo oculto). Nessa mesma direção, o currículo passa a ser definido como "qualquer conjunto de atividades acadêmicas previstas para a integralização de um curso". Essa definição introduz o conceito de atividade acadêmica curricular que precisa, conseqüentemente, ser definida. Entendeu-se por "Atividade Acadêmica Curricular, aquela considerada relevante para que o estudante adquira, durante a integralização curricular, o saber e as habilidades necessárias à sua formação e que contemplem processos avaliativos" (UNIVERSIDADE FEDERAL DE MINAS GERAIS, 2003).

É possível compreendermos, portanto, que a formação curricular do aluno funciona como um caminho a ser delineado por ele. Mas, para o sucesso dessa trajetória, um outro mecanismo é criado com o intuito de guiá-lo: o tutor. Com essas ferramentas postas, torna-se, 
portanto, mais plausível e compreensível a importância da flexibilização vertical e horizontal na formação dos alunos.

\subsubsection{A flexibilização vertical}

A verticalidade encontra sua razão na compreensão temporal da formação dos educandos e na especificidade do conhecimento adquirido por eles. Divide-se em três núcleos: “o núcleo específico, a formação complementar e a formação livre" (UNIVERSIDADE FEDERAL DE MINAS GERAIS, 2003).

O primeiro núcleo, o específico, refere-se às atividades acadêmicas que teriam a função de possibilitar ao aluno os aspectos gerais e fundamentais do campo do saber de sua formação. No caso específico da Biblioteconomia, é garantir as atividades acadêmicas que fundamentam esse saber, como aspectos relacionados à teoria da informação e da comunicação. Integrando esse núcleo, organizar sua estrutura de modo a contemplar os fundamentos históricos, filosóficos, sociológicos e psicológicos da ação biblioteconômica. Além disso, busca possibilitar ao aluno, os possíveis elos de relação de sua área com outras. Do ponto de vista das atividades acadêmicas, esse eixo responsabiliza-se pelas ações curriculares denominadas obrigatórias e optativas. Sua distribuição pode perpassar desde o primeiro até o último período letivo. Nesse sentido, cada curso, por meio de seus colegiados, deverá tecer análise criteriosa sobre as atividades acadêmicas que irão compor este eixo.

O segundo núcleo diz respeito à formação complementar, que trata da especificidade da formação do aluno no curso. No caso do curso de Biblioteconomia da UFPB, as discussões direcionam-se para duas direções (linhas ou ênfases), quais sejam, memória, organização, acesso e uso da informação, e ética, gestão e políticas de informação. Desta forma, existirá uma formação complementar que vise a formação para memória, organização, acesso e uso da informação e outra que forme o bibliotecário na direção da ética, gestão e políticas de informação. É na formação complementar que haverá um primeiro momento de escolha dos alunos quanto à sua formação (a segunda escolha diz respeito ao terceiro eixo curricular, a saber, a formação livre).

A formação complementar divide-se em duas ações curriculares: a formação complementar preestabelecida e a formação complementar aberta. A primeira é definida pelo colegiado do curso, devendo fornecer, por meio de suas atividades acadêmicas, a formação específica. Diríamos que se trata de atividades obrigatórias e de base para sua formação particular. No caso do curso de Biblioteconomia da UFPB é fornecer atividades que ora formem o bibliotecário voltado para memória, organização, acesso e uso da informação, ora o 
formem para ética, gestão e políticas de informação. Já a segunda ação sofre menos "imposição" dos colegiados dos cursos. Sua essência configura-se num primeiro diálogo de ação entre tutor e aluno na escolha de sua formação. É nesse momento que se observa o papel de orientação do tutor no processo de escolhas e de formação acadêmica do aluno, sem esquecer que estas escolhas devem estar em consonância com a especificidade da formação eleita pelo aluno e estabelecida em sua formação complementar preestabelecida. Porém, as atividades acadêmicas apontadas pelo tutor e pelo aluno são autorizadas pelos colegiados dos cursos.

O núcleo relativo à formação livre, isto é, o terceiro eixo, deve corresponder, em termos de percentagem, a 5\% do currículo. Esse momento, para nós, é central, mais uma vez, a relação entre tutor e aluno para uma melhor escolha do aluno na integralização desse conhecimento adquirido. Nessa direção, esse momento marca o interesse individual do aluno para contabilizar os créditos, imprimindo subjetividade de escolha e peculiaridade em sua formação. Essa formação livre pode se dar por meio de "atividades acadêmicas curricular de qualquer curso", que se concretizam pelas atividades acadêmicas denominadas optativas livres (UNIVERSIDADE FEDERAL DE MINAS GERAIS, 2003).

\subsubsection{A flexibilização horizontal}

O princípio que norteia a flexibilização horizontal é o de possibilitar ao aluno o aproveitamento de atividades acadêmicas de cunho complementar e alternativa. Na realidade, neste momento verifica-se a contabilização de diversas atividades acadêmicas desenvolvidas pelo aluno em sua permanência durante o curso. Essas atividades, desenvolvidas pelos alunos e que atualmente não são contabilizadas em seu currículo, mostram-se "tão importantes para a formação do aluno, que é difícil encontrar justificativas para que elas já não estejam sendo utilizadas para tal fim" (UNIVERSIDADE FEDERAL DE MINAS GERAIS, 2003). Nesta direção, reforçando o caráter de diversidade e de flexibilidade na formação do aluno, a flexibilização horizontal apresenta-se como mais um dos aspectos no currículo que atende aos interesses e desejos dos alunos no processo de sua formação.

Porém, para a implementação dessas atividades no currículo, necessita-se, primeiro da autorização prévia do colegiado e, em segunda instância, que tais atividades estejam amparadas por um processo de avaliação institucional.

Dentre várias atividades acadêmicas, os membros da Câmara Estendida de Graduação (UNIVERSIDADE FEDERAL DE MINAS GERAIS, 2003) elencam as seguintes atividades 
acadêmicas de cunho horizontal que podem participar do processo de inclusão curricular na formação dos alunos, a saber:
a) Disciplina;
b) Seminários;
c) Participação em eventos;
d) Discussões temáticas;
e) Atividade acadêmica à distância;
f) Iniciação à pesquisa e docência;
g) Vivência profissional complementar;
h) Estágio curricular.

\section{A ABORDAGEM METODOLÓGICA}

A metodologia desta pesquisa ancorou-se numa abordagem qualitativa em que foram utilizados documentos legais (Leis, Pareceres, Editais e Resoluções) e documentos institucionais (aqui chamamos a atenção para os materiais produzidos pela academia na área pedagógica voltado para discussões referentes ao PPP, currículo e flexibilização curricular e seus enlaces teóricos). Nosso posicionamento neste estudo, tendo como parâmetro a abordagem qualitativa, configura-se em mergulhar num mar hermenêutico em que o sujeito interpretante possa montar e reconstituir as peças que possam explicar, sob dado ponto de vista, o fenômeno pesquisado (MAIA, 2004).

Concordando com essa orientação metodológica, podemos classificar nossa pesquisa como sendo de cunho documental/bibliográfico. Precisamente, quando nos propomos a utilizar uma investigação de caráter documental, partimos do pressuposto de que trata da informação bruta (que precisa ser trabalhada), encontrando-se em qualquer suporte. Partindo do documento, segundo Foucault (2002), o pesquisador visa a recompor a história, estabelecendo os seus elos, rupturas e desconexões. Nesse sentido, ao falarmos de documentos, baseamo-nos nas Leis, Pareceres e Editais, que parecem possibilitar, ao sujeito da pesquisa, essa composição interpretativa.

Já a investigação de teor bibliográfica, para nós, refere-se aos textos acadêmicos especializados que já trazem o seu mapa argumentativo, cabendo-nos, ao acessá-los, refletir e ampliar nossa visão acerca do documento. Nesse sentido, nossa referência encontra-se nos livros e periódicos especializados na área pedagógica e bibliotecária, subsidiando e fundamentando os contextos de nosso estudo. Utilizamos como fundamentação teórica 
autores como Apple (1982), Carvalho (1999), Gadotti e Romão (1997), Giroux (1988), Menegola e Sant'Ana (1999), Saviani (1987, 1991), Silva (1992), Souza (1995), Veiga (1997), Xavier (1998), entre outros que tratam das discussões acerca do PPP, do currículo e de sua flexibilização.

Do ponto de vista da revisão da literatura, esta perpassa itens referentes ao PPP, currículo e flexibilização curricular, uma vez que percebemos a diluição teórica ao objeto de nossa análise encontrada, em sua maioria, nos documentos legais como Pareceres e Resoluções.

Cabe destacar, mais uma vez, a incipiente publicação da literatura sobre flexibilização curricular, fazendo convergir nossas leituras e base da produção textual para o relatório elaborado pela Câmara Estendida de Graduação da Universidade Federal de Minas Gerais (UFMG).

\section{CONSIDERAÇÕES FINAIS E SUGESTÕES}

Pensar em uma sociedade marcada pela flexibilidade e pela diversidade produz efeito em suas variadas instituições. No caso da esfera educativa formal, esse debate ocasiona conseqüências quanto à escolha e desejos dos alunos na sua formação. Permite-nos refletir, ainda, sobre os novos desdobramentos que as instituições de ensino devem passar. Imaginemos que há 60 anos atrás, não se concebia outro espaço de aprendizagem formal além das instituições educativas. Essa visão é paulatinamente substituída à medida que se amplia a compreensão dos espaços de compartilhamento de aprendizagens.

Nessa direção, para a sobrevivência desses ambientes educativos formais, a flexibilização curricular é apontada como elemento inevitável nesse processo, pois possibilita o diálogo ativo entre espaço educativo formal e os outros campos articuladores de saber. Além disso, a flexibilização permite escolhas individualizadas na formação acadêmica de cada aluno, bem como um acompanhamento sistemático e criterioso dos tutores sobre tal formação. Desta maneira, o tutor (professor) assume papel essencial na condução dos alunos em sua formação acadêmica, orientando quanto às escolhas, possibilitando êxito na profissionalização dos formandos $\mathrm{e}$ atendendo a anseios individuais relacionados às necessidades reais do mercado de trabalho.

Podemos conceber a flexibilização curricular como uma possibilidade estratégica dos cursos de formação superior, no intuito de atender às exigências pontuais do campo de 
atuação profissional, favorecendo uma maior conexão entre as informações adquiridas durante o curso e a realidade social que o aluno egresso vai encontrar. Cabe lembrar, ainda, a necessidade do intenso processo de interação entre a esfera formadora (IES) e a esfera de atuação profissional (campo de trabalho), resultando, portanto, em um diálogo salutar entre o espaço público e o privado.

Outro ponto importante de discussão é que tal proposta articula significativo debate entre os professores na formação de seus alunos, uma vez que a maioria das decisões deve ser encaminhada para os colegiados que decidirão sobre as melhores condições de aprendizagem de seus alunos.

É interessante notar, no contexto da flexibilização curricular, dois momentos bem definidos de prática na formação dos alunos no tocante ao estágio: a flexibilização curricular vertical e a horizontal. No que diz respeito à primeira deve ser oferecido pela IES e tem caráter obrigatório. Já a segunda apresenta-se como caráter complementar, ocorrendo em empresas fora do domínio da IES.

A título de sugestão, ainda, o estágio obrigatório pode ser oferecido em três etapas: "Prática bibliotecária I", "Prática bibliotecária II" e "Prática bibliotecária III", pois, observando a estrutura da UFPB, verificamos que há pelo menos dois "laboratórios" para atuação dos alunos de Biblioteconomia: as bibliotecas em seu formato tradicional e o Núcleo de Tecnologia da Informação (NTI), que abriga diversos projetos dentre os quais a construção e manutenção de bibliotecas digitais/virtuais. Desta forma, a disciplina "Prática bibliotecária I" trataria da prática dos alunos em bibliotecas de caráter tradicional (Biblioteca Central da UFPB e suas setoriais). Enquanto que a disciplina "Prática bibliotecária II" poderia relacionar o trabalho biblioteconômico ao espaço virtual, tendo como laboratório o NTI. Para ambas as disciplinas, a avaliação seria contínua, ou seja, no acompanhamento das atividades feitas pelos discentes e na produção de relatório. Para a disciplina "Prática bibliotecária III", o aluno escolheria um desses dois espaços para elaboração e aplicação de um projeto de pesquisa.

No que se refere às disciplinas optativas, as que fariam elo entre a área da Biblioteconomia e outros campos do saber, poder-se-ia estabelecer maior diálogo com os departamentos de Filosofia, Letras, Pedagogia e Comunicação social. Obviamente, outras conexões interdepartamentais poderão surgir, porém, é visível a relação entre a Biblioteconomia e os citados campos. Por exemplo, no que se refere às pesquisas na área de indexação e recuperação da informação, disciplinas como "Lingüística", "Teoria do conhecimento" e "Filosofia da linguagem" parecem estabelecer uma sugestiva relação. A Pedagogia poderia ampliar a relação do bibliotecário nos espaços educativos formais. Já a 
Comunicação social possibilitaria mais debates nos fundamentos da Biblioteconomia enquanto ciência.

Outro aspecto a ser retomado, no que diz respeito a flexibilização curricular, é a iniciação científica. A escolha do aluno nessa modalidade deve refletir maturidade quanto à sua formação, que, neste caso, estará em sintonia com a inserção da pesquisa e capacitação profissional voltada para atuar em programas e projetos de teor científico. Por isso, é conveniente que, só por volta do terceiro ano de curso, os discentes passariam a concorrer para bolsas de pesquisa e de ensino. Seria o momento de escolher de forma mais consciente a sua formação profissional para pesquisa e docência. Esta escolha "tardia" reflete duas preocupações. A primeira preocupação trata-se de dar oportunidade a quem de fato desejaria especificar sua atuação profissional nesta área. Já a segunda preocupação diz respeito à racionalização de custos, pois observamos bolsas de iniciação científica inférteis, ou seja, alunos que se inserem em projetos sem maturidade e discernimento quanto à suas escolhas e, portanto agravam esta situação, quando concluem os projetos sem a efetiva preparação.

Podemos dizer que a presente pesquisa trata de apontar para um primeiro caminho para se pensar a reformulação do currículo de Biblioteconomia, contemplando um projeto maior, que diz respeito a uma sensível abertura de escolha dos alunos em seus processos formativos.

Além disso, perceber a intrínseca articulação da pós-graduação com a graduação. No processo de formação dos alunos, existirão aqueles que terão um encaminhamento para determinadas áreas específicas do mercado de trabalho, porém, um outro segmento deverá ter formação que contemple a pesquisa, a fim de assumir atividades acadêmicas e docência. Nessa direção, a flexibilidade curricular necessita de um planejamento cuidadoso, visando às necessidades do mercado e às necessidades internas de cada IES para formação de um grupo de pesquisadores qualificados.

\section{REFERÊNCIAS}

ARIÈS, Philippe. História social da criança e da família. 2. ed. Rio de Janeiro: LTC, 1981.

ASSOCIAÇÃO BRASILEIRA DE EDUCAÇÃO EM CIÊNCIA DA INFORMAÇÃO ABECIN. Proposta de Diretrizes Curriculares para os Cursos de Biblioteconomia.

Disponível em: <http://www.abecin.org.br/Textos/DiretrizesCIMecVersao2.doc $>$. Acesso em: 20 jan. 2005. 
BICUDO, Maria Aparecida Viggiani; SILVA JÚNIOR, Celestino Alves da (Org.). Formação do educador e avaliação institucional: avaliação institucional, ensino e aprendizagem. São Paulo: Unesp, 1999.

BRASIL. Lei no 9394, de 20 e dezembro de 1996. Estabelece as Diretrizes e Bases da Educação Nacional, Brasília, DF, 1998.

Resolução CNE/CES nº 19, de 13 de março de 2002. Estabelece as Diretrizes Curriculares para o curso de Biblioteconomia. Diário Oficial da União. Conselho Nacional de Educação. Câmara de Educação Superior, Brasília, DF, 2002.

Resolução CNE/CES no 1.363 , de 25 de janeiro de 2002. Retificação do Parecer CNE/CES n. 492/2001, que trata da aprovação das Diretrizes Curriculares Nacionais para o Curso de Biblioteconomia. Conselho Nacional de Educação. Câmara de Educação Superior. Disponível em: <http://www.mec.gov.br/cne/pdf/CES1363.pdf >. Acesso em: 20 dez. 2004.

. Resolução CNE/CES nº 9.131, de 12 de dezembro de 2001a. Retificação do Parecer CNE/CES n. 492/2001, que trata da aprovação das Diretrizes Curriculares Nacionais para o Curso de Biblioteconomia. Conselho Nacional de Educação. Câmara de Educação Superior. Disponível em: <http://www.mec.gov.br/cne/pdf/CES9131.pdf>. Acesso em: 20 dez. 2004.

. Resolução CNE/CES no 492, de 3 de abril de 2001b. Diretrizes Curriculares para o curso de Biblioteconomia. Conselho Nacional de Educação. Câmara de Educação Superior. Disponível em:

$<$ http://www.google.com.br/search?q=cache:I58PT_jW6S8J:www.mec.gov.br/sesu/ftp/parece res/49201FHGSCCLBAM.doc+Parecer+CNE/CES+492/2001\&hl=pt-BR\&ie=UTF-8>.

Acesso em: 20 dez. 2004.

CARVALHO, Luciana Moreira. O bibliotecário e o mercado da documentação popular: CPDCs. Informação e Sociedade: estudos, João Pessoa, v. 9, n. 2, p. 439-454. 1999.

FLEXIBILIZAÇÃO curricular. Disponível em:

$<$ http://www.arquit.ufpr.br/graduacao/flexibilizacao.htm>. Acesso em: 17 jan. 2005.

FOUCAULT, Michel. A arqueologia do saber. 6. ed. Rio de Janeiro: Forense Universitária, 2002.

A ordem do discurso: aula inaugural no Collège de France, pronunciada em 2 de dezembro de 1970. 6. ed. São Paulo: Loyola, 2000.

FREIRE, Paulo. Ação cultural para a liberdade. Rio de janeiro: Paz e Terra, 1979.

Pedagogia da autonomia. Rio de Janeiro: Paz e Terra, 1996.

GADOTTI, Moacir. Projeto político-pedagógico da escola: fundamentos para a sua realização. In: GADOTTI, Moacir; ROMÃ̃O, José Eustáquio (Org.). Autonomia da escola: princípios e propostas. São Paulo: Cortez, 1997. 
GIROUX, Henry. Escola crítica e política cultural. São Paulo: Cortez, 1988.

MAIA, Manuela Eugênio. Das tecnologias que agem sobre os corpos: as relações de poder nas instituições educativas modernas. 2004, 127f. Dissertação (Mestrado em Educação) Universidade Federal da Paraíba, João Pessoa, 2004.

MENENGOLA, Maximiliano; SANT'ANA, Ilza Martins. Por que planejar? Como planejar? Currículo, área, aula. Petrópolis: Vozes, 1999.

MOREIRA, Antônio Flávio. Currículos e programas no Brasil. 8. ed. São Paulo: Papirus, 1990.

MOREIRA, Antônio Flávio; SILVA, Tomaz Tadeu da (Org.). Currículo, cultura e sociedade. 6.ed. São Paulo: Cortez, 2002.

MORIN, Edgar. Os sete saberes necessários à educação do futuro. São Paulo: Cortez, 2001 .

OLIVEIRA, Romualdo Portela (Org.). Política educacional: impasses e alternativas. São Paulo: Cortez, 1995.

ORLANDI, Eni Pulcinelli. Discurso e leitura. São Paulo: Cortez, 2001. Interpretação: autoria, leitura e efeitos do trabalho simbólico. Petrópolis: Vozes, 1998.

SAVIANI, Dermeval. Pedagogia histórico-crítica: primeiras aproximações. São Paulo: Cortez, 1991.

Política e educação no Brasil. São Paulo: Cortez: Autores Associados, 1987.

SAVIANI, Nereide. Saber escolar, currículo e didática. São Paulo: Autores Associados, 1997.

SILVA, Carmen Silvia Bissolli; MACHADO, Lourdes Marcelino (Org.). Nova LDB: trajetória para cidadania? São Paulo: Arte \& Ciência, 1998.

SNYDERS, Georges. A pedagogia em França nos séculos XVII e XVIII. In: DEBESSE, Maurice; MIALARET, Gaston. Tratado das ciências pedagógicas. São Paulo: Nacional/ USP, 1974.

SOUZA, Francisco das Chagas de. O ensino de biblioteconomia nova no Brasil: o marco da construção de um projeto de ensino superior. Florianópolis: Preliminar, 1995.

TAKAHASHI, Tadao (Org.) Sociedade da Informação no Brasil: Livro Verde. Brasília, DF: Ministério da Ciência e Tecnologia, 2000.

UNIVERSIDADE FEDERAL DE MINAS GERAIS (UFMG). Câmara Estendida de Graduação. Desafios atuais da universidade. Campo Grande: maio 2003. Disponível em: <http://www.ufmg.br/prograd/flex/todo.html>. Acesso em: 17 jan. 2005. 
ULHÔA, Joel Pimentel de. Reflexões sobre a leitura em filosofia. Goiânia: Editora da UFG, 1997.

XAVIER, Antônio Carlos da R.; AMARAL SOBRINHO, José. Como elaborar o Plano de Desenvolvimento da escola - PDE. Brasília, DF: Projeto Nordeste/FUNDESCOLA, 1998.

VEIGA, Ilma Passos Alencastro (Org.). Projeto político-pedagógico da escola: uma construção possível. Campinas: Papirus, 1997.

\begin{abstract}
This article presents questions concerning the syllabus of the Library Science School at the Universidade Federal da Paraíba. The methodology is based on a qualitative approach, and the main data come from legal sources (laws and similar normative pieces) and institutional sources (registered discussions about the pedagogical policies projects [PPPs], formal proposals, and others). In sketching our proposal of flexibility of curricula, we focus on some strategic actions which aim to strengthen the connection between the courses offered and labor market. Besides, we discuss the flexibility of the syllabus as a tool to expande/garantee the students' right to choose the convenient subjects to their academic formation; to strengthen the academic self-management of the Schools; and to stimulate the School staff (especially teachers) to assume a more reflective attitude toward the internal demands concerning their courses.
\end{abstract}

KEY WORDS: Pedagogical Policies Project. Syllabus Flexibility.

Originais recebidos em 16/03/2006. 